\title{
POPULAÇÃO IDOSA E COMUNICAÇÃO PÚBLICA: PRÁTICAS CIDADÃS EM PLATAFORMAS DIGITAIS ${ }^{1}$
}

\author{
DENISE REGINA STACHESKI \\ Universidade Tuiuti do Paraná \\ Curitiba, Paraná, Brasil \\ e-mail: denise.stacheski@utp.br
}

1 A pesquisa teve o apoio da CAPES - Coordenação de Aperfeiçoamento de Pessoal do Ensino Superior - Brasil, projeto n. 13744-12-7. 
POPULAÇÃO IDOSA E COMUNICAÇÃO PÚBLICA: PRÁTICAS CIDADÃS EM PLATAFORMAS DIGITAIS

Resumo: Novas demandas emergem na comunicação pública frente ao enveIhecimento populacional brasileiro. Este artigo mapeia iniciativas europeias, vinculadas ao Ano Europeu do Envelhecimento Ativo, publicadas no documento Age Plataform Europe (2011). A abordagem dialógica norteia o estudo. Percebe-se, ao fim, que é possível criar redes de relacionamentos digitais, para mobilizar e engajar o público idoso em sua participação e deliberação pública. Palavras chaves: envelhecimento, cidadania, plataformas digitais.

\section{ANCIANOS Y COMUNICACIÓN PÚBLICA: PRÁCTICAS CIUDADANAS EN PLATAFORMAS DIGITALES}

Resumen: Las nuevas demandas surgen en la comunicación pública a través del envejecimiento de la población brasileña. En este artículo se mapea las iniciativas europeas, vinculadas con el Año Europeo del Envejecimiento Activo, publicado en el documento Edad Plataforma Europa (2011). El enfoque dialógico guía el estudio. Está claro, después de lo cual usted puede crear redes de relaciones digitales, movilizar y comprometer al público en su antigua participación pública y la deliberación.

Palabras clave: envejecimiento, la ciudadanía, las plataformas digitales.

\section{ELDERLY AND PUBLIC COMMUNICATION: CITIZEN PRACTICES IN DIGI-}

\section{TAL PLATFORMS}

Abstract: New demands emerge in public communication across the brazilian population aging. This article maps European initiatives, linked to the European Year of Active Ageing, published in document Age Platform Europe (2011). The dialogic approach guides the study. It is clear, after which you can create networks of digital relationships, mobilize and engage the public in their old public participation and deliberation.

Keywords: aging, citizenship, digital platforms. 


\section{1 enVELHECIMENTO POPULACIONAL E A COMUNICAÇÃo PÚBliCA.}

No Brasil, o censo realizado pelo IBGE, em 2010, afirma que o percentual de idosos cresceu nas últimas décadas e superou o número de crianças com até quatro anos. De acordo com a pesquisa, o país já tinha naquele ano mais de 20 milhões de idosos (IBGE, 2010). A população muito idosa, com 80 anos ou mais, também aumenta. Entre 1970 e 2000 esse grupo aumentou de 485,4 mil pessoas ( $0,5 \%$ do total populacional) para 1,8 milhão ( $1,1 \%$ do total); em 2020, estima-se que chegará a quase 6 milhões de pessoas, compondo 2,7\% da população total brasileira Do grupo muito idoso há, no país, um contingente de 25 mil pessoas acima de 100 anos de idade (IBGE, 2010).

Idosos que pertencem a um segmento populacional que necessita de novas demandas nas políticas públicas e nos rumos da coletividade frente às significações sobre o envelhecimento. Zenaide e Viola (2011, p. 11) seguem com essa perspectiva:

Uma sociedade que se pretende democrática não pode descuidar de educar seus cidadãos para a construção de uma sociabilidade que reconheça a pessoa idosa como sujeito de dignidade e direitos, como parte constitutiva da sociedade, que necessita de proteção, educação, saúde, segurança, seguridade social, mas também, que necessita da liberdade e da participação ativa nas decisões relativas às políticas públicas.

A projeção é que em 2025 o Brasil tenha 32 milhões de idosos, saltando para a $6^{\text {a }}$ colocação mundial. Com uma forte redução da taxa de crescimento populacional, o envelhecimento da população brasileira se torna um fato irreversível e atinge diretamente toda a sociedade, seus costumes e, principalmente, as políticas públicas. $\mathrm{O}$ crescimento da população idosa coloca em discussão múltiplas dimensões sociais, como o desgaste fisiológico, o prolongamento da vida, o desequilíbrio demográfico e o custo financeiro das políticas sociais. A Organização das Nações Unidas - ONU (2002) - acredita que as modificações demográficas encontram o desafio de aumentar as oportunidades de pessoas idosas aproveitarem ao máximo suas capacidades de participação em todos os aspectos da vida.

Apesar dos progressos ocorridos nos últimos anos, por meio de movimentos públicos voltados à população idosa (STACHESKI, 2013), ainda há a necessidade de um diálogo maior com as pessoas mais velhas - pois a representação 
POPULAÇÃO IDOSA E COMUNICAÇÃO PÚBLICA

negativa de pessoais idosas ainda é constante na sociedade brasileira. Significações produzidas no dia-a-dia, nas interações comunicativas entre os membros de uma coletividade que, juntos, promovem a dinâmica da produção/reprodução da cultura em uma sociedade a partir de uma abordagem dialógica (BAKHTIN, 1997). Este estudo parte da premissa bakhtiniana que a consciência dos sujeitos adquire forma e existência a partir de signos e significações criados por um grupo organizado em função da história de suas práticas sociais. Assim, a voz que o idoso constrói em relação ao envelhecimento é uma adaptação às possíveis expressões midiáticas - existentes no social - na esfera pública. Essa imagem, introspectiva e subjetiva do idoso, não pode ser separada da realidade de sua orientação numa situação social existente - contemplando, aqui, os projetos e políticas públicas.

A população idosa apenas atingirá uma representatividade quando, além da autonomia e independência, se tornar ativa tanto pela participação social e cultural quanto pelo engajamento cívico-político (MATOS, 2011), ativado pelas práticas e processos da comunicação pública. Enfrentar o desafio para consolidar uma comunicação pública direcionada aos idosos é tarefa para o aprofundamento da democracia e para o bem-estar de um segmento populacional em vertiginoso crescimento que, na maioria das vezes, é considerado uma categoria problemática do ponto de vista demográfico, econômico, sociopsicológico, filosófico e de saúde pública (MATOS, 2011).

O reconhecimento e a participação cívica são de extrema relevância para compreender aspectos ligados à construção de habilidades políticas e à necessidade de negociação de interesses por atores que têm seu status social fragilizado, como alguns idosos (MATOS, 2011). Existe, assim, a necessidade de ampliar canais de comunicação, de adotar medidas e projetos para que idosos sintam-se inclusos no cotidiano, com acesso a meios de expressão e com formas de garantir a cidadania nas práticas sociais, sem vitimização da velhice ou sem uma super valorização. É preciso fomentar a participação, a voz ativa e cidadã de idosos na sociedade - inclusive pelas plataformas digitais - pelos processos e práticas de comunicação da atualidade.

Por certo, considera-se a desigualdade nas condições de vida dos idosos, bem como todas as suas particularidades. O envelhecimento é um processo heterogêneo (como toda fase da vida) e se vincula aos aspectos sociais, históri- 
cos e econômicos de cada sujeito. Goldfarb (1998) trabalha com a questão das diferentes visões do envelhecimento e pergunta:

Então, de que realmente falamos quando falamos de velhice? E quando falamos do velho? Do velho reivindicativo que briga com todo mundo e por tudo, ou do velho passivo que aceita seu destino sem reclamar? Do velho engajado, ativo e divertido, ou do outro deprimido e solitário? Daquele que vive em família ou do que foi depositado em um asilo? Da velha elegante que passeia nos bairros nobres, ou da faxineira que ainda ajuda a criar os netos? Do velho que trabalha a nosso lado ou daquele que renunciou a lutar? Dos que renunciaram à sexualidade ou dos que reivindicam seu direito ao prazer? Dos que vemos na fila do banco ou no banco da praça? Da velha "bruxa"? Do velho "sábio"? Do doente? Dos poderosos ou dos marginalizados?

Diferentes visões e concepções sociais. Imagens que são constituídas socialmente, por meio de significações que são refletidas ou refratadas (BAKHTIN, 1997) na infância, na idade adulta e na velhice.

Diante da contextualização apresentada, o objetivo deste artigo é mapear iniciativas europeias, vinculadas ao Ano Europeu do Envelhecimento Ativo, publicadas no documento Age Plataform Europe (2011), que articulam práticas cidadãs por meio de plataformas digitais direcionadas à população idosa. 0 estudo justifica-se para que as modelagens já implementadas por países que contam com uma alta porcentagem de idosos, em sua população, sejam divulgadas e, posteriormente, analisadas com o intuito de, talvez, adaptá-las às demandas da comunicação pública brasileira.

\section{IDOSOS E PLATAFORMAS DIGITAIS}

Idosos são a parcela da população que mais cresce como usuária das plataformas digitais. Em 2010, houve um aumento de 20\% do número de pessoas acima de 50 anos que usavam a Internet no Brasil (IBGE, 2010).

A pesquisa desenvolvida pelo SESC/SP (2007) e pela Fundação Perseu Abramo (2007) demonstrou que idosos usuários das tecnologias de informação e comunicação definem novos hábitos que interferem diretamente em seu cotidiano. Segundo pesquisas desses institutos, a média mensal de permanência on-line de idosos chega a 32h40m. Os horários preferidos são entre as 7h e 10h 
POPULAÇÃO IDOSA E COMUNICAÇÃO PÚBLICA

da manhã, e o local de acesso são suas residências. Além de buscar informações, valorizam a socialização e as interações intergeracionais (SESC/SP; FUNDAÇÃO PERSEU ABRAMO, 2007).

As interconexões digitais favorecem a formação de uma arena conversacional, uma diferente forma de sociabilidade, uma interação social entre os sujeitos que pode acontecer por meio da troca de e-mails, chats, grupos eletrônicos, listas de discussão e, principalmente, por meio das práticas de comunicação nas redes sociais digitais, como o Facebook, o Twitter, o Hi5, o My Space, entre outras. Goldman (2002) salienta que as relações virtuais podem se transformar em relações reais que beneficiam o idoso em seu aspecto psicossocial e ampliam seu grupo conversacional. Mesmo com a fragilidade inicial dos contatos virtuais, essas relações geralmente, se aprofundam e se tornam mais sólidas.

Ao abordar as redes sociais digitais é importante salientar que a formação de redes sociais é uma prática humana muito antiga, caracterizada, por Castells (2003), pela geração, pelo processamento e pela transmissão da informação como fontes fundamentais de produtividade e poder. Recuero (2009, p. 17) também afirma que não é novo o estudo das redes. Para a autora, "o estudo da sociedade a partir do conceito de rede representa um dos focos de mudança que permeia a ciência durante todo o século XX - quando começaram a despontar estudos que focam para o fenômeno como constituído das interações entre as partes".

As redes são definidas, de forma geral, como um conjunto de nós interconectados, adaptáveis, flexíveis, constituindo um conjunto produzido pelas interações humanas. Para Scherer-Warren (1999, p.06), a rede pode ser definida como uma articulação de diversas unidades que, "através de certas ligações, trocam elementos entre si, fortalecendo-se reciprocamente, e que podem se multiplicar em novas unidades, as quais, por sua vez, fortalecem todo o conjunto, na medida em que são fortalecidas por ele". As diferenças entre as redes sociais presenciais e as redes sociais digitais são definidas por Scherer-Warren (2007, p. 39) da seguinte maneira:

As redes sociais interindividuais ou coletivas caracterizam-se por serem presenciais, em espaços contíguos, criando territórios no sentido tradicional do termo, isto é, geograficamente delimitados; enquanto, isso, as redes virtuais, resultantes do ciberativismo, são intencionais, transcendem as fronteiras espaciais das redes presenciais criando, portanto territórios virtuais cujas configurações se definem pelas 
adesões por uma causa ou por afinidades políticas, culturais e ideológicas. Todavia elas poderão vir a ter impacto sobre as redes presenciais e vice-versa numa constante dialética entre o local e o global.

A autora destaca que a diferença principal se encontra em relação aos espaços geográficos no qual ocorre a formação das redes sociais. Nas redes sociais presenciais destaca-se o território delimitado, próximo. Já nas redes sociais digitais - a grande característica se encontra na adesão por afinidades políticas, culturais ou ideológicas, mesmo sem contiguidade física. Estilos de vida, nas redes sociais digitais, definem mais do que o espaço geográfico dos sujeitos participantes. As redes sociais - digitais ou não - são relações entre as pessoas. Uma interação que busca objetivos particulares ou por outras causas. Um conjunto de sujeitos que participam de práticas comunicacionais por meio de suas afinidades - motivando várias mudanças concretas nos sujeitos sociais, em suas coletividades e nas organizações envolvidas. Portanto, existe uma interligação que não pode ser vista ou analisada sozinha e, sim, pelo contexto em geral.

As redes sociais digitais se constituem a partir do reflexo das ações e pensamentos que os sujeitos possuem de outros relacionamentos sociais; são espaços públicos que agregam uma continuação (uma extensão) dos enunciados, valores, representações, constituídos por toda a experiência vivenciada.

\section{MODELAGENS EUROPEIAS: PLATAFORMAS DIGITAIS}

O objeto empírico deste artigo consiste em modelagens europeias que articulam práticas cidadãs por meio de plataformas digitais direcionadas à população idosa - contidas no documento oficial Age Plataform Europe (2011).

As iniciativas são mapeadas a partir de uma abordagem dialógica a partir de Bakhtin (1997) que percebe a estrutura da realidade do sujeito como um processo histórico e social. O filósofo russo argumenta que não existe fala isolada - mas, uma fala complexa e formada pelo plano social. Por meio da concepção dialógica da linguagem, Bakhtin (1997) concebe a expressão individual e social originária do ambiente em que se vive, das interações culturais, políticas e econômicas. Assim, ao verificar as iniciativas públicas para ampliar o diálogo com a população idosa, os países europeus estão constituindo possibilidades para que 
o processo de envelhecimento de seus cidadãos possa ser melhor sucedido - ao possibilitar canais de voz social, de participação ativa e deliberação pública.

A Europa é a região mais envelhecida do mundo, com um índice de enveIhecimento de 136,2 idosos para cada 100 crianças entre 0 - 14 anos (MARQUES, 2011). A União Europeia estipulou 2012 como o "Ano Europeu do Envelhecimento Ativo". Os países articularam uma série de investimentos e ações voltados à população acima de 65 anos - ao envolver idosos em práticas de sociabilidades, de tecnologias de informação e comunicação, de cultura e de ações intergeracionais. Assim, vários projetos foram implantados - com o intuito de fomentar a participação do idoso europeu em sua comunidade, em suas deliberações públicas, no fortalecimento de sua voz social.

$\mathrm{Na}$ Europa, o documento oficial Age Plataform Europe (2011) traz várias iniciativas articulando a apropriação das redes sociais digitais por idosos. Segundo o documento, duas frentes de projetos se destacam no envolvimento de idosos em práticas cidadãs e no desenvolvimento para as facilidades nas redes sociais digitais:

Ensure active citizenship of older people

An important aspect of active ageing in society is ensuring that older people have access to political and civic processes. This is important both to ensure that these processes take account of the needs of older people and as a means of ensuring broader participation in society of older people. Local and regional actors can play an important role in overcoming some of the barriers to such active citizenship. Some ideas have been around working with small groups of older people to get their voice heard and facilitating access to Internet-based services.

Facilitate social networks.

Participating in social networks is a key facilitator of other forms of participation in society. Local and regional actors can do much to help older people network and thus help them to participate in their preferred activities, continue to learn and to engage with friends, family and neighbors. European education and research programmes can be particularly useful in finding new ways to promote social networking. 
Compreende-se o efeito da inclusão social experienciado por idosos nas novas mídias pelo fato de que as plataformas digitais multiplicam suas oportunidades de se integrarem à sociedade, se apropriarem dos códigos, dos meios, e da linguagem da sociedade atual. Neste caso, a comunicação pública pode modelar redes sociais digitais para incentivar o diálogo, a participação cidadã e a discussão de problemas da coletividade.

A seguir, projetos implantados na Europa que envolvem a ativação do idoso a participações nas redes sociais digitais objetivando a deliberação pública. São iniciativas que podem servir de exemplos para a implementação das redes sociais digitais como canais de participação em assuntos da comunidade.

\section{Rede AgeingWell}

Descrição e comentário:

A iniciativa da rede AgeingWell visa construir e ativar uma rede europeia focada na melhoria da qualidade de vida de idosos, promovendo a aceitação pelo mercado de soluções de tecnologias de informação e comunicação para o envelhecimento bem sucedido. Para atingir o seu objetivo, o projeto AgeingWell desenvolve diretrizes para a implantação e a partilha das melhores práticas entre centros de competências tecnológicas para idosos e aumenta a consciência dentro da comunidade europeia sobre o envelhecimento (Age Plataform Europe, 2011). A exemplo da rede Ageing Well, as redes sociais digitais devem ser pensadas como plataformas da comunicação pública, "com alcance e influência suficiente para marcar território no ambiente midiático e agendar os debates públicos" (RIBEIRO, 2010, p. 127) porque proporcionam aos sujeitos o estabelecimento de redes de relacionamento, a partir de compartilhamento de conteúdos e de experiências de interesses comuns. As redes sociais, além de se formarem pela afinidade de interesses entre os sujeitos que buscam nas plataformas digitais um espaço para as suas manifestações, também se sustentam pela "liberdade que seus participantes encontram para se manifestar da forma que Ihes parece mais conveniente e confortável” (RIBEIRO, 2010, p. 129). As plataformas digitais podem facilitar a organização, a mobilização e a expressão democrática. Destaca-se que a tecnologia não promove a democracia direta, mas o meio público e político não é (e não poder ser) insensível às mudanças 
POPULAÇÃO IDOSA E COMUNICAÇÃO PÚBLICA

tecnológicas. As plataformas digitais têm a capacidade de reforçar as instituições da sociedade civil que mediam cidadãos e Estado (NORRIS, 2001).

\section{ADD ME! - Activating Drivers for Digital Empowerment in Europe - (Co-funding: ICT-PSP).}

Descrição e comentário:

ADD ME! É uma rede pan-europeia com mais de 20 organizações, em 10 países europeus, trabalha com iniciativas de apoio a grupos desfavorecidos no uso de novas tecnologias. Um dos três grupos-alvo são "idosos, pobres idosos e aposentados". O grupo de trabalho explora diversas formas inovadoras de sucesso envolvendo pessoas em risco de exclusão e as ligando aos prestadores de serviços locais e regionais. Os métodos incluem a Internet, tele quiosques, telefones móveis e TV interativa (Age Plataform Europe, 2011). A partir do mapeamento de iniciativas como o ADD ME! constata-se que as potencialidades, advindas da facilidade de acesso à informação e pelo aumento das oportunidades de comunicação, são subutilizadas pelo governo brasileiro, principalmente, quando o público é a população idosa. As redes sociais digitais podem não gerar participação política, mas consistem em um espaço propício por privilegiar elementos fundamentais da democracia, como o acesso a diversas fontes de informação e à possibilidade de expressão por práticas de comunicação cada vez mais facilitadas.

\section{Later Life - Social networking for senior citizens - (Co-funding: Grundtvig).}

Descrição e comentário:

O Later Life é um projeto que tem como objetivo ampliar os benefícios sociais modernos das tecnologias de informação e comunicação para idosos. A principal ferramenta é uma plataforma de rede social on-line que fornece uma ampla gama de conteúdo relevante, exclusivamente, para pessoas mais velhas. O projeto oferece apoio e orientação aos usuários idosos e àqueles que trabaIham com eles. O projeto também incentiva a acessibilidade, incluindo software de cooperação com prestadores de serviços locais e regionais para processar o 
conteúdo on-line mais acessível (Age Plataform Europe, 2011). Acessibilidade é o ponto chave deste projeto mapeado. Ressalta-se, assim, que para cada segmento populacional é necessário criar estratégias e instrumentos apropriados à realidade das pessoas. No caso de idosos, o intuito não é vitima-los socialmente devido às debilidades fisiológicas ou isolamento social, mas, fortalecer diferentes valores positivados para a velhice, como o envelhecimento bem sucedido, a valorização de sua voz e papel social, o fortalecimento de sua cidadania e a participação política. Corroborar na tomada de decisão democrática provavelmente traz maior envolvimento do idoso nas políticas públicas principalmente em relação às suas próprias demandas.

\section{Go-myLife: Going Online: My Social Life (Co-funding: AAL Joint Programme).}

Descrição: Go-MyLife é um projeto que visa melhorar a participação social das pessoas idosas através da utilização de redes sociais on-line. É uma plataforma de rede social digital personalizada para as necessidades dos idosos, permitindo interações com seus pares e famílias. As redes também fornecem acesso fácil a bases de informação relevantes para apoiar o idoso. O projeto objetiva o aumento da qualidade de vida dos idosos e facilita a sua participação social (Age Plataform Europe, 2011). Constata-se no mapeamento deste projeto a necessidade de perceber um idoso ativo, que participa de sua comunidade. É imprescindível que a cidadania perpasse, principalmente, pelo fato de que cidadão seja um emissor nos processos comunicacionais de sua sociedade e uma peça chave no sistema de interação midiático. Acredita-se que a comunicação pública, pelas práticas comunicacionais das redes sociais digitais, possibilita maior aproximação entre representantes e representados idosos ao estabelecer uma nova relação entre cidadãos e políticas, um diálogo entre os promotores de políticas, os produtores midiáticos e os atores individuais. Matos (2010) assevera que na medida em que se promove a interação, a participação da sociedade nas decisões políticas ocorre de forma ativa, pois o cidadão busca não somente os direitos de pertencer ao sistema sociopolítico, mas o direito de participar na (re)elaboração do sistema como um todo. Nas redes sociais digitais, idosos têm um canal de expressão que permite a emissão e a visibilidade 
POPULAÇÃO IDOSA E COMUNICAÇÃO PÚBLICA

de múltiplos pontos de vista. Uma discussão com interesses distintos, com um potencial de manifestação pública e política de idosos comuns que poderiam dialogar com o governo, com o Estado, dos seus lares, sem a necessidade de mediações. Uma maior participação cidadã dos idosos faria com que outras significações de mundo circulassem na coletividade frente ao envelhecimento.

As iniciativas acima são projetos inseridos em uma promoção de políticas na busca de um envelhecimento bem sucedido na Europa que poderia servir de exemplo para ações públicas brasileiras. Em relação às novas mídias, até agosto de 2013, não se encontraram iniciativas governamentais brasileiras que ativassem o processo de deliberação pública ou debate participativo nas questões da comunidade para idosos, permeando as redes sociais digitais ou as tecnologias de informação e comunicação. Os projetos brasileiros se direcionam aos cursos e treinamentos na área de informática. Talvez, o primeiro passo para ações futuras. São ações, no entanto, que não se apropriam das tecnologias de informação e comunicação para o envolvimento da população idosa nos debates públicos.

\section{CONCLUSÃo}

Os idosos estão cada vez mais presentes em nossas casas (pais, avós, tios, bisavós) em nossas instituições de ensino (como colegas, professores e colaboradores), estão nos supermercados (trabalhando), nas praças (conversando), nos shoppings (consumindo), nas academias de ginástica (muitas vezes com maiores disposições que os adultos jovens), nas mídias (revelando-se), nas manchetes policiais (criminosos e vítimas de violências absurdas), nos congressos acadêmicos (repassando experiências de vida), no Twitter, no Facebook (interagindo, conversando, brincando) etc. No entanto, em muitos aspectos, a sociedade brasileira ainda não está preparada para lidar com novas concepções culturais e significações sociais da velhice.

Necessita-se da participação e protagonismo do idoso para exercitar o papel de agente na transformação social. Com isso, estabelecer um processo de comunicação dirigida para os diferentes públicos, como para a população idosa, com ações específicas, se torna uma estratégia necessária para acender o envolvimento dos cidadãos no diálogo público, uma cultura de comunicação pública que transcenda a informação e promova o diálogo, com um envelhecimento heterogêneo. 
Para Mattelart (2000, p.170) as mídias digitais "passam a fazer parte do debate sobre a possibilidade de um espaço público em escala planetária". O autor também argumenta que "em todas as latitudes, a problemática da transformação do espaço público, nacional e internacional, tende, aliás, a ocupar lugar de destaque nas abordagens críticas inspiradas pela sociologia, pela ciência política e pela economia política". As redes sociais digitais se constituem a partir do reflexo das ações e pensamentos que os sujeitos possuem de outros relacionamentos sociais; são espaços públicos que agregam uma continuação (uma extensão) dos enunciados, valores, representações, constituídos por toda a experiência vivenciada.

Não se considera, nesta tese, as redes sociais digitais como meios inerentes para o engajamento cívico ou para o aumento do capital social de idosos, contudo, acredita-se que as redes sociais digitais são lugares de voz de que idosos podem se apropriar para efetivar sua participação cidadã. O espaço de transmissão de informações e diálogo com a opinião pública, provavelmente, se fortalece através das redes sociais digitais.

Essas redes potencializam práticas da comunicação pública pelo princípio de que se deva priorizar o debate social. Transformam-se em espaços de interação social e de trocas de conteúdos que discutem temas e assuntos de relevância pública e interesse público, neste estudo, direcionados aos idosos, pelos idosos e com os idosos. Objetivam tornar o processo de comunicação mais interativo e participativo, em uma remodelação da esfera política - modificando os padrões de discurso, as relações entre representantes e representados, o acesso dos cidadãos à participação - "uma nova realidade midiática” (DUARTE, 2009, p. 96).

A comunicação pública brasileira precisa encontrar caminhos para trabaIhar a elevação da autoestima e do reconhecimento do idoso brasileiro no seu papel como cidadão, na reivindicação plena de seus direitos, na adoção de uma postura autônoma e na busca de uma percepção ampliada da comunidade onde vive, a partir da heterogeneidade no envelhecimento.

\section{REFERÊNCIAS}

AGE PLATAFORM EUROPE (2011). Disponível em: www.age-platform.eu/. Acesso em: dez./2012. ANO EUROPEU DO ENVELHECIMENTO ATIVO. Ano Europeu do Envelhecimento Ativo e da Solidariedade entre Gerações. Programa de Ação, 2012, Portugal. Governo de 
POPULAÇÃO IDOSA E COMUNICAÇÃO PÚBLICA

Portugal, 2012.

BAKHTIN, M. Marxismo e filosofia da linguagem. São Paulo: Hucitec, 1997.

DUARTE, J. (org.). Comunicação pública: Estado, governo, mercado, sociedade e interesse público. São Paulo: Atlas, 2009.

GIACOMIN, K. O papel do Conselho Nacional dos Direitos do Idoso na elaboração e implementação de políticas públicas no Brasil. In: Revista dos Direitos da Pessoa Idosa. Governo do Brasil, Secretaria de Direitos Humanos da Presidência da República - SDH/PR, 2011. Disponível em: http://portal.mj.gov.br/sedh/3cndpi/doc/Revista_DireitosPessoa_Idosa.pdf. Acesso em: jun./2012.

GOLDMAN, S. N. Internet e envelhecimento: um estudo exploratório de salas de bate-papo, 2002. Disponível: www.sbgg.org.br/profissional/artigos/Internet.htm. Acesso em: fev./2011.

GOLDFARB, D. C. Corpo, tempo e envelhecimento, 1998. São Paulo: Casa do Psicólogo Livraria e Edit. Ltda. Disponível no site:www.portaldoenvelhecimento.net/artigos/corpo.pdf. Acesso em janeiro/2010.

IBGE-Instituto Brasileiro de Geografia e Estatística. Condição de vida. Disponível em: http:// www.ibge.gov.br/home/estatistica/populacao/condicaodevida/indicadoresminimos/sinteseindicsociais2010/SIS_2010.pdf. Acesso em: jul./2010.

. Disponível em: <http://www1.ibge.gov.br/ibgeteen/datas/idoso/politica_do_idoso_no_brasil.htm>. Acesso em: ago./2009

. Disponível em http://www.ibge.gov.br/ibgeteen/datas/idoso/idoso_no_mundo. html. Acesso em: jun./2012.

KACHAR, V. A terceira idade e a inclusão digital. Revista O mundo da Saúde, São Paulo, v. 26, n. 3, 2002.

MANZINI-COVRE, M.L.O que é cidadania? São Paulo: Brasiliense, 1993

MARQUES, S. Discriminação da terceira idade. Lisboa: FFMS, 2011.

MATELLART, A. A globalização da comunicação. Bauru: EDUSC, 2000.

MATOS, H. Capital social e comunicação. Interfaces e articulações. São Paulo: Summus, 2009.

. O potencial do capital social na comunicação pública. Observatório de Imprensa, ano 16, n 698, 2010. Disponível em: http://www.observatoriodaimprensa.com.br/ news/view/o-potencial-do-capital-social-na-comunicacao-publica. Acesso em: mai./2012. - O declínio do capital social e comunicacional na terceira idade e a ausência de reconhecimento dos idosos. In: MARQUES, A.; MATOS, H. Comunicação e política. Capital social, reconhecimento e deliberação pública. São Paulo: Summus Editorial, 2011.

NORRIS, P. Digital divide: civic engagement, information poverty, and the Internet worldwide. Cambridge: Cambridge University, 2001. 
ORGANIZAÇÃO DAS NAÇÕES UNIDAS (ONU). Plano de ação internacional sobre o envelhecimento, 2002. Disponível em: www.cicts.uevora.pt/paienv.pdf. Acesso em jan./2010.

. O envelhecimento da população brasileira: perspectivas e desafios, 2002. Disponível em: http://www.tropicologia.org.br/conferencia/2002envelhecimento_populacao.html. Acesso em: jan./2010.

RECUERO, R. Redes sociais na Internet. Porto Alegre: Sulina, 2009.

RIBEIRO, A. A. Produção e distribuição de vídeos institucionais para transmitir conhecimento: a experiência do Ministério Público de Santa Catarina no Youtube. Tese de Doutorado da Universidade Federal de Santa Catarina, do Programa de Engenharia e Gestão do Conhecimento, 2010. Disponível em: http://www.aberje.com.br/monografias/\%C3\%82ngelo_Augusto_Ribeiro.pdf. Acesso em: mai./2012.

RUBIM, A.A.C. Cidadania, comunicação e cultura. In: PERUZZO, CM.K.; DE ALMEIDA, F.F. (org.). Comunicação para a cidadania. São Paulo: Intercom; Salvador: UNEB, 2003.

SCHERER-WARREN, I. Cidadania sem fronteiras - ações coletivas na era da globalização. São Paulo: Hucitec, 1999.

2001. . Movimentos sociais: um ensaio de interpretação sociológica. Florianópolis: UFSC, . Redes sociais: trajetórias e fronteiras. In: DIAS, Leila Christina; SILVEIRA, Rogério Leandro Lima (org.). Redes, sociedades e territórios. 2.ed. Santa Cruz do Sul: EDUNISC, 2007 SESC/SP; FUNDAÇÃO PERSEU ABRAMO. Idosos no Brasil. Vivências, desafios e expectativas na terceira idade, 2007. Disponível em: http://www2.fpa.org.br/uploads/1_perfil_sociodemografico_idosos_brasileiros.pdf. Acesso em mai./2012.

STACHESKI, D.R. O idoso brasileiro na comunicação pública. Cidadania e representações sociais num sistema de interação midiático. Tese de doutorado da Universidade Tuiuti do Paraná, no Programa de Pós Graduação em Comunicação e Linguagens. PR, Curitiba, 2013.

ZENAIDE, M. N.; VIOLA, S. A. Educação em direitos humanos na promoção de uma cultura de respeito aos direitos da pessoa idosa. In: Revista dos Direitos da Pessoa Idosa. Governo do Brasil, Secretaria de Direitos Humanos da Presidência da República - SDH/PR, 2011. Disponível em: http://portal.mj.gov.br/sedh/3cndpi/doc/Revista_DireitosPessoa_Idosa.pdf. Acesso em: jun./2012.

RECEBIDO EM: 11/10/2013

ACEITO PARA PUBLICAÇÃO: 20/11/2013 
POPULAÇÃO IDOSA E COMUNICAÇÃO PÚBLICA

\section{Denise Regina Stacheski}

Doutora e mestre em Comunicação e Linguagens pela Universidade Tuiuti do Paraná (UTP). Especialista em Gestão de Recursos Humanos pela FESP/PR (1999) e Graduada em Comunicação Social - Relações Públicas pela Universidade Federal do Paraná (1998). Autora de dois livros: Comunicação empresarial e correspondência (lesde Brasil S.A., 2010) e A pequena empresa e as interações tecnológicas (Combook, 2013). Docente da Graduação de Comunicação Social e Coordenadora do MBA em Gestão da Comunicação Pública em Empresarial da Universidade Tuiuti do Paraná. 